\title{
Vol.1 No.3, Autumn 2020 \\ Predictive Factors of Mammography Based on Health Belief Model in Healthy Volunteers in Isfahan City Healthcare Centers
}

\author{
Nasiri Isfahani $\mathrm{S}^{1}$, Rajabi $\mathrm{N}^{2 *}$, Zakeri $\mathrm{P}^{3}$
}

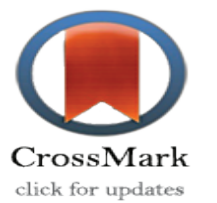

1- Health Education Dept, School of Public Health, Shahid Beheshti University of Medical Sciences, Tehran, Iran.

2- MSc Student in Epidemiology, School of Public Health, Isfahan University of Medical Sciences, Isfahan, Iran

3- MSc Student in Biostatistics, School of Public Health, Isfahan University of Medical Sciences, Isfahan, Iran.

Corresponding Author: Rajabi N, MSc Student in Epidemiology, School of Public Health, Isfahan University of Medical Sciences, Isfahan, Iran

Email: rajabi.naser94@gamil.com

Received: 6 May 2019

Accepted: 30 September 2019

\section{Abstract}

Introduction: Cancer, such chronic and non - contagious diseases, is known to its importance, due to the changes in the incidence of diseases in the world and the profound psychological impact of the disease on the foundation of family, and community. Breast cancer is the most common type of cancer and is the second reason for deaths in women. Mammography is the most accurate method of distinction and diagnosis of breast cancer at the early stages in many countries and can identify non-touch waste and help to detect tangible masses.

Method: The present study is of a cross-sectional base manner that has been carried out on 160 healthy volunteers from the healthcare unit of the city of Isfahan. Sampling was carried out in accessible manner. The data collection tool was a multi-part questionnaire including awareness questions, demographic characteristics, behavior, and behavioral intention and standardized questionnaire (Champion's Health Belief Model). The collected data were analyzed with SPSS Version 16 software. Participation in this study was informed consent. Results: Also, in this study, the highest percentage of research units (53 percent) in the age group were under 45 . The median age of the participants was 46.52 with a standard deviation of $7.06 .145(90.6 \%)$ of the participants so far were informed about breast cancer, a source of information (62.5\%) 100 of the physicians and health centers employees. Regarding the evaluation of model constructs in the field of breast cancer and breast self-examination, 98 (61.2\%) persons with moderate knowledge, 122(76.2\%) persons with low perceived susceptibility, 105 (65.6\%) Of the subjects with moderate perceived severity,93 (58.1\%) persons had moderate perceived benefits and $110(68.8 \%)$ persons had moderate perceived benefits.

Conclusion: The results of the study showed that the level of behavior and behavioral intentions of mammography in healthy volunteers is low. The results of this study also reveal the need for more attention of health planners in the country to educate and promote screening methods and remove barriers.

Keywords: Mammography, Healthy Volunteers, Health Belief Model, Related factors.

\begin{tabular}{|l|l|}
\hline \multicolumn{3}{|c|}{ Access this article online } \\
\hline
\end{tabular}




\title{
عوامل بيشكويىكننده انجام ماموكر افى بر اساس مدل اعتقاد بهداشتى در رابطين بهداشتى مراكز بهداشتى در مانى شهرى اصفهان
}

\author{
ساناز نصيرى اصفهانى'، ناصر رجبى "*، يريسا ذاكرى"

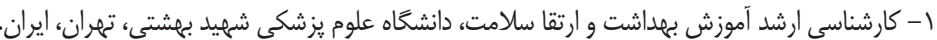

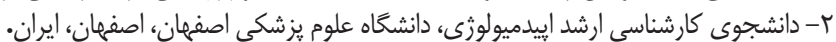

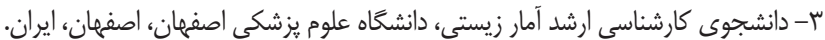

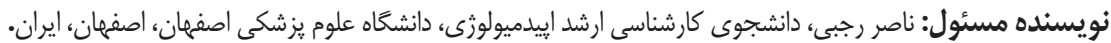
ايميل: rajabi.naser94@gamil.com

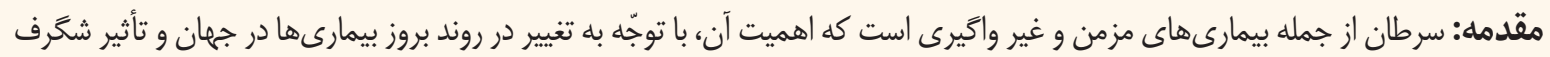

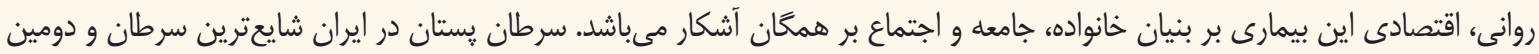

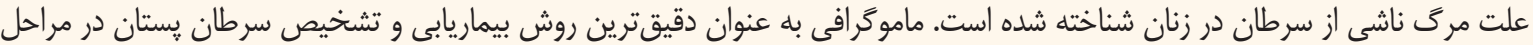
اوليه در بسيارى از كشورها به كار برده مىشود و مىتواند ضايعات غيرقابل لمس را شناسايى كرده و به تشخيص تودههاى قابل لمس كمى بـ

روش: مطالعه حاضر از نوع مقطعى مىباشد كه روى •عا نفر از رابطين بهداشتى مراكز بهداشتى درمانى شهرى شهرستان اصفهان انجامشده

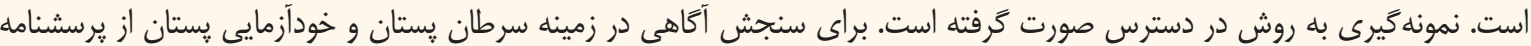
محقق ساخته و براى سنجش اعتقادات بهداشتى هم از يرسشنامه استانداردشده جممييون (Champion’s Health Belief Model Scale)

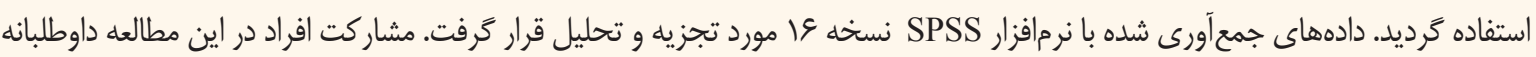
و با بايت آكاهانه صورت كرفت.

يافتهها: در مطالعه حاضر بيشترين درصد واحدهاى يزوهشى (سه درصد) در كروه سنى زير هأ سال بودند. ميانكَين سنى شركت كنندكان

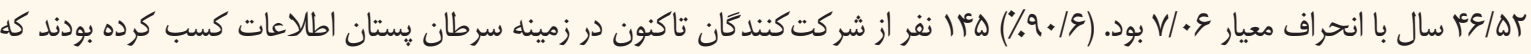

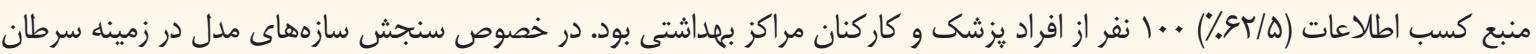

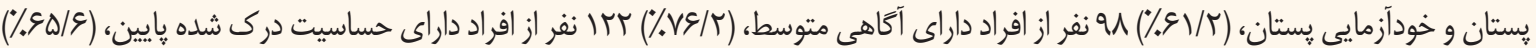

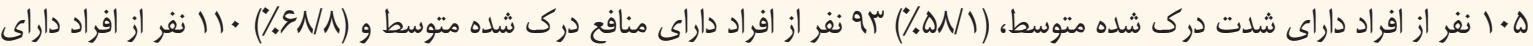
موانع درك شده متوسط بودند. نتيجه كَيرى: نتايج حاصل از مطالعه نشان داد كه سطح رفتار و قصد رفتارى ماموَّرافى در رابطين بهداشتى بايين مىباشد. همجنين نتايج اين

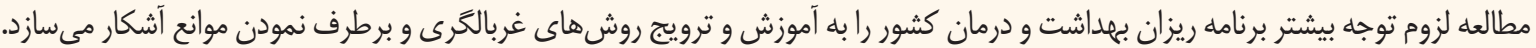
كليدوازه ها: ماموكًرافى، رابطين بهداشتى، الخَوى اعتقاد بهداشتى، عوامل مرتبط.

جهان و تأثير شَرف روانى، اقتصادى اين بيمارى بر بنيان خانواده، مقلدمه

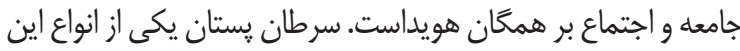

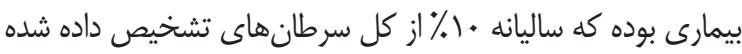
در سراسر جهان را به خود اختصاص مىدهد (؟). سرطان پستان در ايران شايعترين سرطان و دومين علت مرك ناشى از سرطان در زنان سرطان از جمله بيمارىهاى مزمن و غير واكيرى است كه كروه وسيعى از بيمارى ها بالغ بر • •rانوع بيمارى را شامل شده و مانند ساير

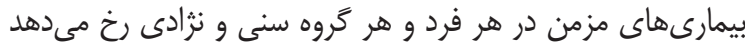
(1). اهميت اين بيمارى، با توجّه به تغيير در روند بروز بيمارى هـا درى درى 
خصوص مشخص كردن عوامل مؤثر بر تغيير رفتار بكار مىروند

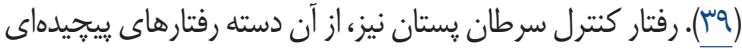
مىباشد كه تحت تأثير عوامل مختلفى ازجمله عوامل روانشناختى انتي، شخصيتى و اجتماعى قرار دارد، بنابراين براى بررسى دلايل انجام يا

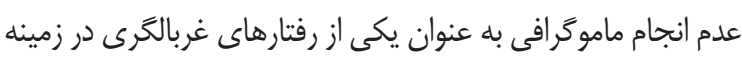
اين بيمارى بايد از مجموعلى علوم رفتارى، اجتماعى و يزشكى إنى

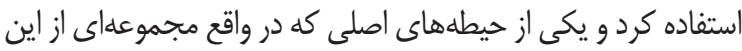

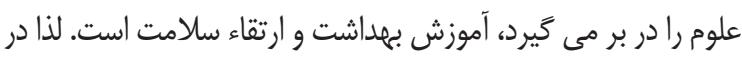
مطالعه حاضر تلاش شد با استفاده از يكى از ير كاربردترين الكوهاى

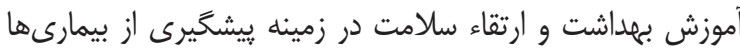
و سرطانها و نيز رفتارهاى غربالكرى (الكوى اعتقاد بهداشتى)، به اله

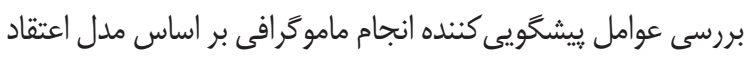
بهداشتى در رابطين بهداشتى مراكز بهداشتى درمانى شهرى اصفهان بران بران

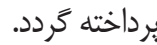

\section{روش مطالعه}

مطالعه حاضر از نوع مقطعى (Cross sectional) بوده كه روى • نفر از رابطين بهداشتى مراكز شهرى شهرستان اصفهان در سال كه از طريق نمونهَّيرى به روش در دسترس انتخاب شدند، انجام شد. افراد واجد شرايط براى شركت در مطالعه، از ميان لا مركز بهداشتى شهرستان اصفهان انتخاب شدند. شرايط ورود به مطالعه شامل عدم باردارى و شيردهى (با توجه به تغييرات فيزيولوزيكى

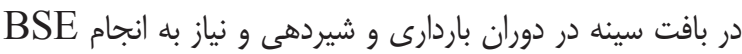
در طول مطالعه، اين كروه از مطالعه خارج شدند) و نداشتن سابقه شخصى ابتلا به سرطان يستان بوده است. ابزار گردآورى دادهها

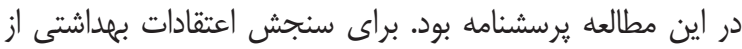

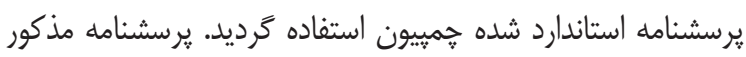
در سال 1941 جهت استفاده بينالمللى طراحى شد و در سال 1997

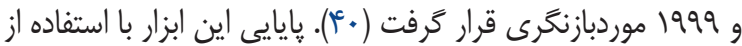

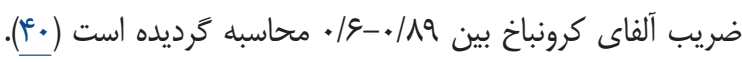
يرسشنامه شامل اطلاعات دموًرافيك (سن، وضعيت تأهل، سطح تحصيلات رابط و همسرشان در صورت متأهل بودن، داشتن سابقه خانوادگى و منبع كسب اطلاعات در خصوص سرطان پستان)، سطح

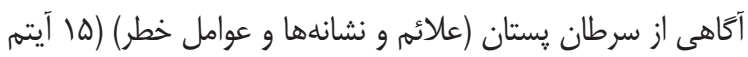

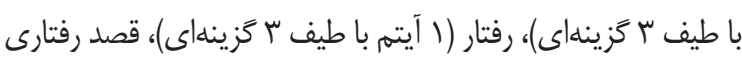

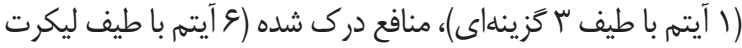
ه كزينهاى) و موانع درك شده (9 آيته با طيف ليكرت ه كزينهائ)

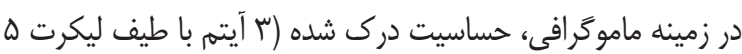

شناخته شده است (V-Y). ميزان بروز استانداردشده (ASR) كل كشور براى جمعيت زنان \&/F د در صد هزار و براى جمعيت مردان

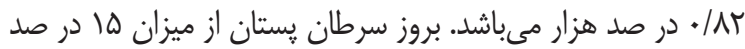
هزار نفر در مناطق شهرى تا و/عب در كلانشهرها متغير است. امّا نكته اساسى، روند رو به رشد سرطان يّتان در ايران است به طورى

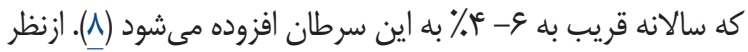

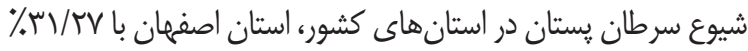
سوّم ين استان شايع بعد از تهران و يزد كزارش شده است (1) (1-9).

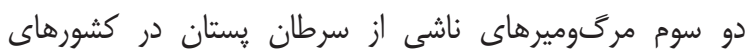

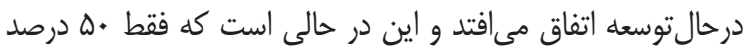
از موارد سرطان يستان تشخيص داده شده در جهان، در كشورهاى درحالتوسعه مىباشد (T)). اين مسئله به دليل وجود ارتباط مستقيه ميان ميزان مركى و مير ناشى از اين بيمارى با مرحله بيمارى در زمان تشخيص بوده و نشاندهندهى ضرورت تشخيص به موقع سرطان

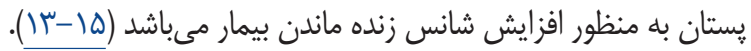
ماموكرافى به عنوان دقيقترين روش بيماريابى و تشخيص سرطان يستان در مراحل اوليه در بسيارى از كشورها به كار برده مىشود و و مىتواند ضايعات غيرقابل لمس را شناسايى كرده و به تشخيص تودههاى قابل لمس كمك كند. (1). شواهد كافى دال بر اينكه

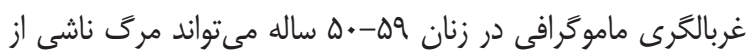

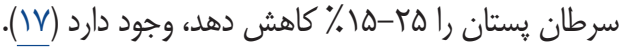
مطالعات كَوناگونى كه در سطح ايران و جهان انجام شده، بيانكًر اين واقعيت مىباشد كه آكاهى زنان در مورد علائم، نشانهها و عوامل

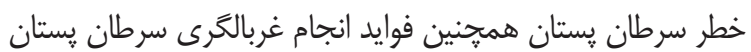
در زمانى كه هنوز هيج علامتى ندارد كم تا متوسط مىباشد و در اين

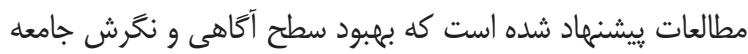

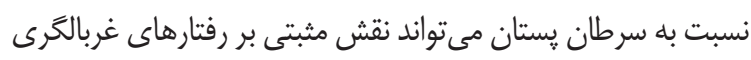

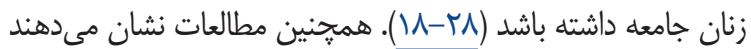
كه باورها و موانع فرهنكى، نخرانى از تشخيص موارد غيرطبيعى،

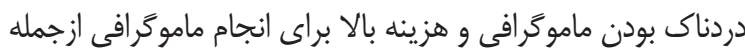

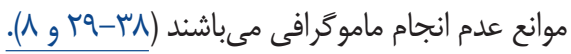
در عصر حاضر كه بيمارى هاى مزمن و غير واگيردار ازجمله سرطانها در حال جايخزينى با بيمارىهاى واگيردار و عفونى هستند، نياز به تحول در رويكردهاى سلامت و نغاهى دوباره به مقوله يِيشخيرى از

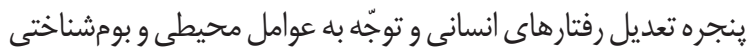
احساس مى گردد (^^ّ). در خصوص تعديل رفتارهاى انسانى مىتوان كفت، اكتساب يك رفتار جديد بلصورت يكى اتفاق يكباره نبوده

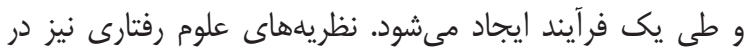




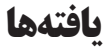

در مطالعه حاضر بيشترين درصد واحدهاى يزوهشى (سمان

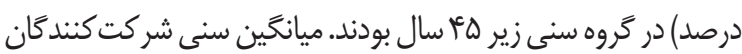


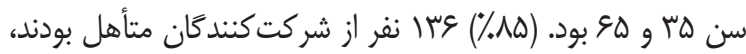

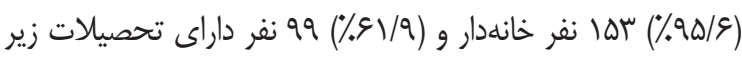
دييلم بودند. (•r\%) رץ نفر داراى سابقه خانوادگى ابتلا به سرطان

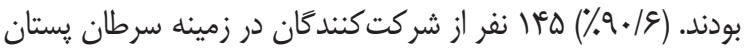
اطلاعات كسب كرده بودند كه منبع كسب اطلاعات در (ه/ وآ٪)

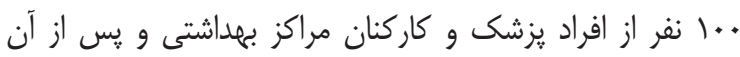

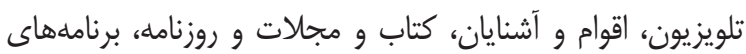
راديويى و اينترنت منابع كسب اطلاعات ذكرشده بودند (نمودار ).
كزينهاى) و شدت درك شده (V آيتم با طيف ليكرت ه كزينهاى) نسبت به سرطان پستان بود. همجنين براى سنجش آكاهى در زمينه

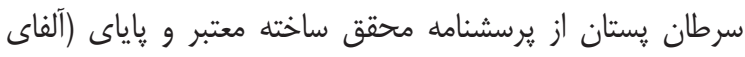

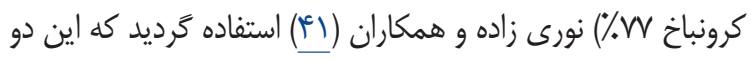

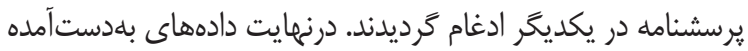
بانرمافزار SPSS نسخه عا مورد تجزيه و تحليل قرار كرفت. از آمار توصيفى براى محاسبات و تعيين فراوانى مشخصات دموكًافيك،

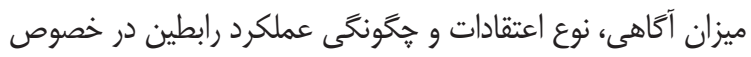
ماموكرافى استفاده شد. مشاركت افراد در اين مطالعه داوطلبانه و با رضايت آكاهانه صورت كَرفت. اين مقاله حاصل كار بإيانامها

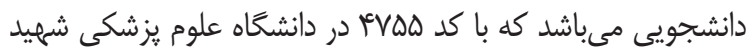
بهشتى به تصويب رسيده است.

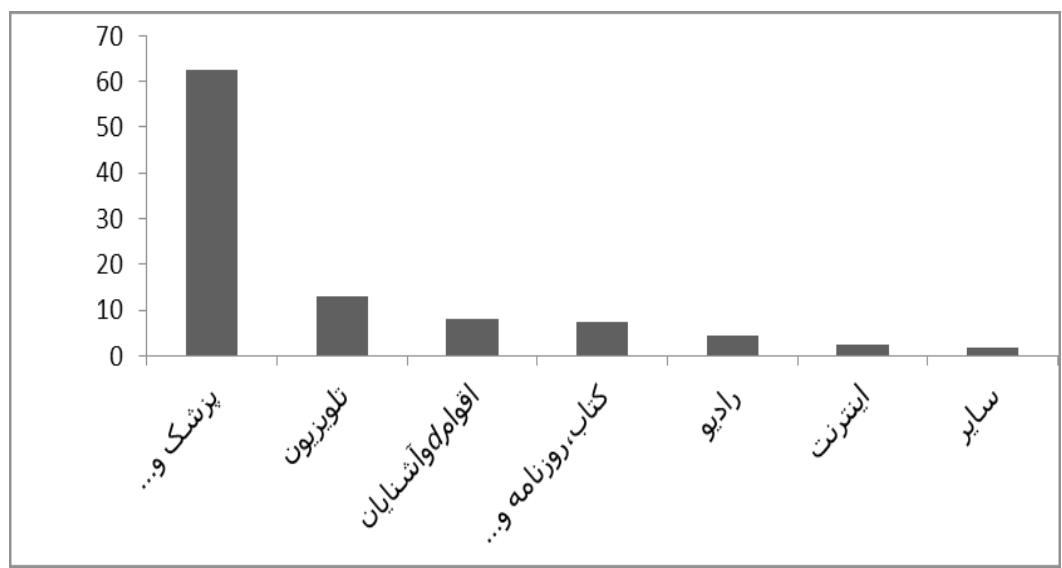

نمودار () توزيع فراوانى منابع كسب اطلاعات رابطان بهداشتى

(T/\%) r نفر داراى حساسيت درك شده بالابودند. از نظر شدت درك شده در

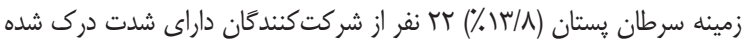

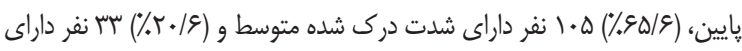

شدت درى شده بالابودند (جدول ().

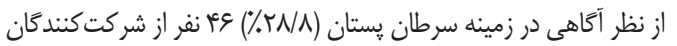

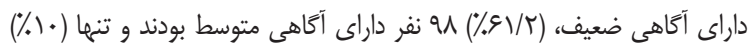
عا نفر از رابطين تحت مطالعه از آكاهى سطح بالا برخوردار بودند. ازنظر حساسيت

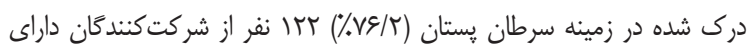
حساسيت درك شده پإيين، (ه/r\%\%) عץ نفر داراى حساسيت درك شده متوسط جدول (: توزيع فراوانى سازههاى الكَوى اعتقاد بهداشتى در سه سطح بالا، متوسط و پإيين

بالا

$(\%) \mathbf{N}$

$19(\%)$

$r(\%) / r)$

r $(\% / r / q)$

QD $(\%+\% \cdot / 9)$

er $(\%, r g / T)$
متوسط

(\%) N

$91(\% 91 / T)$

זद $(\% / \% / \Delta)$

1. $\Delta(\%$ (\% $\% / 8)$

9) $(\% \Delta N / 1)$

$11 \cdot(\% .9 N / \Lambda)$
يايين

(\%) N

is $(\%$ TN/A)

IrT $(\%$ \% $\% / r)$

r $(\% / \mu / \Lambda)$

$r(\%) / r)$

$\wedge(\% \Delta)$
سطوح

شناست منافع درك شرى شدى شده شده

سازه 
نيز قصد و نظرى براى انجام ماموكرافى در آينده نداشتند. همجنين

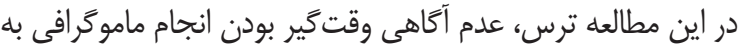
عنوان اصلىترين موانع انجام اين رفتار شناخته شدهاند (جدولي آ).

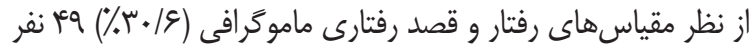
از رابطين طبق كَفته خود، ماموكَ افى را بهطور منظهم انجام مى دادند

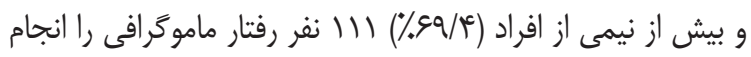

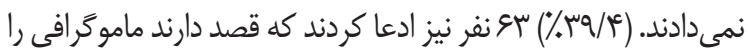

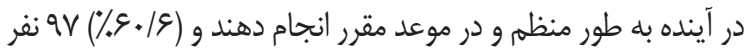

جدول r: توزيع فراوانى مطلق نمره سؤالات موانع درك شده در افراد مورد يُوهش الفش

\begin{tabular}{|c|c|c|c|c|c|c|}
\hline \multicolumn{2}{|c|}{ 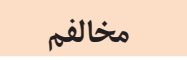 } & \multicolumn{2}{|c|}{ نظرى ندارم } & \multicolumn{2}{|c|}{ 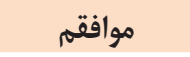 } & \multirow{2}{*}{ سؤالات موانع درى شداسخ هاه } \\
\hline درصد & 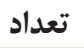 & درصد & 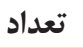 & درصد & 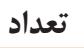 & \\
\hline$r r / \Delta$ & צ" & r. & r & $\Delta V / \Delta$ & 94 & اكر ماموگر افى بحيرم و مورد بدى در يستانم ديده شود، مىترسم. \\
\hline$I V / \Delta$ & ru & mI/T & ఎ. & $\Delta 1 / r$ & Ar & از ماموگًرافى مىترسم جون نمىدانم קكار مى كنند. \\
\hline $\mathrm{W} / \Lambda$ & r. & $f i / r$ & ब9 & f. & se & نمى دانم كه براى گرفتن ماموگرافى خه اقدامى بايد انجام دهم. \\
\hline$\Delta \varphi / F$ & $\wedge \mathrm{V}$ & $r / \Lambda$ & ऍ & $r / 9$ & ra & از انجام ماموكر افى خجالت مى كشم. \\
\hline r. & זr & r/ג & ऍ & $\Delta \varepsilon / T$ & q. & انجام مامو كَرافى يا عكسبردارى وقت گير است. \\
\hline rN/ & is & $r r / \Delta$ & ar & $r q / 4$ & r & انجام ماموكرافى دردناك است. \\
\hline $19 / 4^{c}$ & 新 & $T r / \Delta$ & ar & YN/1 & v & زمان انجام ماموگر افى را از ياد مىبرم. \\
\hline $19 / 4$ & 山 & $m \in / c$ & $\Delta \Delta$ & $\mid \varphi / 4$ & $v^{e}$ & مشكلات بيشترى در مقايسه با كرفتن ماموكر افى دارم. \\
\hline$V / \Lambda$ & 111 & $r M / 9$ & ra & $r / f$ & $\checkmark$ & براى كرفتن ماموكَ افى منظه، خيلى يير هسته. \\
\hline
\end{tabular}

به اطلاع رسانى در خصوص سرطان يستان و روشهاى غربالكرى

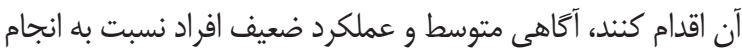
ماموكر افى نشاندهنده عدم ارائه اطلاعات و آموزش كافى به افراد إداد مىباشد. بديهى است كه رسانههاى گروهى و متصديان امر آموزش همكانى بلخصوص سيستمهاى بهداشتى در اين راستا مسئوليت

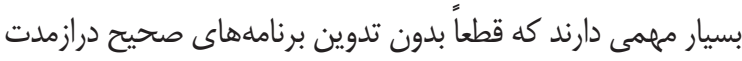
و مستمر تحقق آن ميسر نخواهد بود. ياقتهها، نشان مىدهد كه در برد مطالعه حاضر منبع اصلى كسب اطالاعات در زمينه سرطان پستان و رفتارهاى غربالكرى آن بزشى و كار كنان مراكز بهداشتى بودهاند

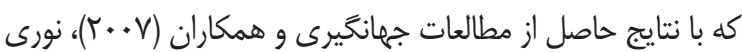
زاده و همكاران (•(1+r) در تطابق بود؛ بنابراين با توجه به اين نكته كه كار كنان مراكز بهداشتى مىتوانند بهعنوان اصلىترين منبع كسب

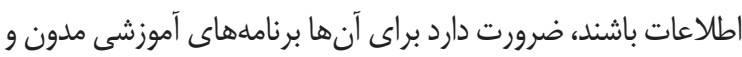
نظريه محور در نظر كرفته شود تادر انتقال اطلاعات در جامعه مؤثرتر

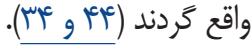

\section{نتيجه}

مطالعه حاضر اطلاعات ارزشمندى را در مورد عوامل ييشكويى كننده انجام ماموگر افى بر اساس مدل اعتقاد بهداشتى در رابطين بجداشتى مراكز بهداشتى در اختيار قرار داد. نتايج مطالعه حاضر نشاندهندهى

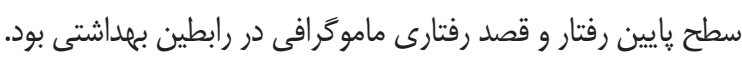
با توجه به تأثير شَّرف روانى، اقتصادى اين بيمارى بر بنيان خانواده،

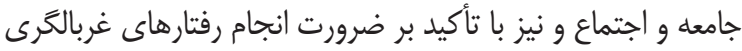

مطالعه حاضر از نوع مقطعى بوده كه بر روى •عا نفر از رابطين

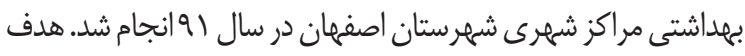
مطالعه بررسى عوامل ييشكَيى كننده انجام ماموكر افى بر اساس مدل اعتقاد بهداشتى در رابطين بهداشتى مراكز بهداشتى درمانى شهرى برى براسئ

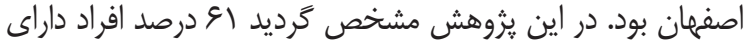

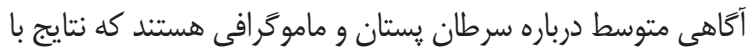
مطالعه ميرى و همكاران هم سويى دارد. آنان در مطالعه خود نشان هرئن

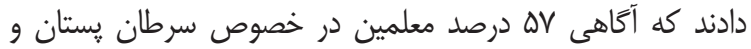

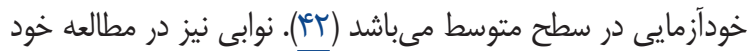
كه ميزان آَاهى و نكَرش دانشجويان دختر دانشكده ادبيات و فنى درانى مهندسى دانشخاه سيستان و بلوحستان را در اين مورد بررسى كرده است ميزان آكاهى افراد را متوسط (•ه درصد) كزارش كرده است

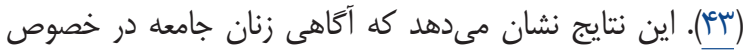
سرطان پِستان و ماموكرافى متوسط بوده و نياز به توجه بيشتر در

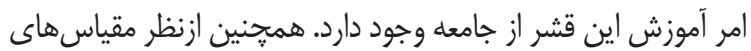

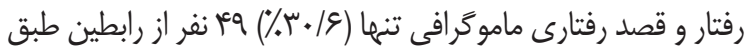
كَته خود، ماموكر افى را بلطور منظه انجام مى دادند كه با مطالعات

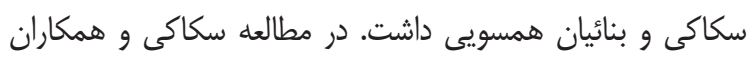
درصد افراد ماموكر افى انجام داده بودند. در مطالعه بنائيان و همكاران

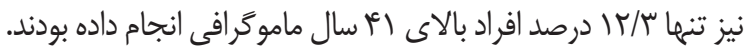

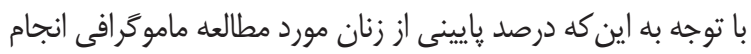

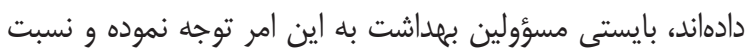


ساناز نصيرى اصفهانى و همكاران

اعتقاد بهداشتى جهت بهبود و ارتقاء قصد رفتارى و رفتار ماموگرافى

$$
\text { در رابطين بهداشتى توصيه مىشود. }
$$

\section{References}

1. Siegl R, Ward E, Brawley O, Jemal A. Cancer statistics, 2011: The impact of eliminating socioeconomic and racial disparities on premature cancer deaths. Cancer Journal for Clinicans 2011; 61(4): 212 - 236.

2. Hartley EM, Hoch MC, Cramer RJ. Health Belief Model and Theory of Planned Behavior: A Theoretical Approach for Enhancing Lower Extremity Injury Prevention Program Participation. International Journal of Athletic Therapy \& Training. 2018; 23 (1):16-20.

3. Shiraly R, AsadollahiKh, Asadollahi P. Risk perception and preventive issues for breast cancer among female employees. Iranian Journal of Cancer Prevention 2010; 3(4): 166- 173. (Persian).

4. Noori Zadeh R, Bakhtary Aghdam F, Sahebi L. Knowledge, health beliefs and breast cancer screening behaviors of women referring to health centers of Tabriz,2010. Iranian Journal of Breast Diseases 2010; 3 (3): 43-51. (Persian).

5. Nafisi N, SaghafiNiya M, Akbari M A, Najafi S. Survey to determine knowledge and attitudes of women towards breast cancer. Breast Diseases Quartery of Iran 2010; 3 (3): 28 - 33. (Persian)

6. Masoudiyekta L, Rezaei-Bayatiyani H, Dashtbozorgi B, Gheibizadeh M, Malehi AS, Moradi M. Effect of Education Based on Health Belief Model on the Behavior of Breast Cancer Screening in Women. Asia-Pacific Journal of Oncology Nursing. 2018; 5 (1): 114 - 20.

7. Montazeri A, Vahdaninia M, Harirchi I, Harirchi AM, Sajadian A, Khaleghi F, et al. Breast cancer in Iran: need for greater women awareness of warning signs and effective screening methods. Asia Pacific Family Medicine 2008; 7 (1): 6 - 15. (Persian).

8. Kambiz Abachizadeh* , Abdorreza Moradi Kouchi , Ali Ghanbari Motlagh , Ahmad Kousha , Reza Shekarriz-Foumani, Amir Erfani. Breast Cancer in Iran: levels, Variations and Correlates. Social Health, Volume:5 Issue:1, 2018. P. 11- 15. (Persian).

9. Moodi M, Sharifirad GR, Tahergorabi Z. Mostafavi F. Get to know breast cancer pathway
جهت كمك به تشخيص زودرس و كاهش عوارض و مرگ و مير ناشى از سرطان يستان، انجام مداخلات آموزشى مبتنى بر الكَى

toward health. 1st ed. Isfahan: Publication of Medical University of Isfahan; 2011. Pp. 12- 80. (Persian).

10. Guilford K, McKinley E, Turner L. Breast Cancer Knowledge, Beliefs, and Screening Behaviors of College Women: Application of the Health Belief Model. American Journal of Health Education. 2017; 48 (4): 256 - 63.

11. Tuzcu A, Bahar Z, Gozum S. Effects of Interventions Based on Health Behavior Models on Breast Cancer Screening Behaviors of Migrant Women in Turkey. Cancer Nursing. 2016; 39 (2): E40 - E50.

12. Hajian-Tilaki K, Auladi S. Health belief model and practice of breast self-examination and breast cancer screening in Iranian women. Breast Cancer. 2014; 21 (4): 429 - 34.

13. Taymoori P, Moshki M, Roshani D. Facilitator Psychological Constructs for Mammography Screening among Iranian Women. Asian Pacific Journal of Cancer Prevention. 2014; 15 (17): $7309-16$

14. Zhaohui L, Xiaoming W, Shengwen G,Binggang Y. Diagnosis of breast cancer tumor based on manifold learning and support vector machine. Proc. IEEE Int. Conf. Information and Automation. 2008. 20-23: Changsha. Pp.703710.

15. Wang WL, Hsu SD, Wang JH, Huang LC, Hsu WL. Survey of breast cancer mammography screening behaviors in Eastern Taiwan based on a health belief model. Kaohsiung Journal of Medical Sciences. 2014; 30 (8): 422-7.

16. Anagnostopoulos F, Dimitrakaki C, Niakas D, Tountas Y. Validity and reliability assessment of health belief scales for mammography screening in Greek asymptomatic women. PsychoOncology. 2013; 22 (8): 1912 - 7.

17. American Cancer Society. Find cancer early: cancer screening guidelines. Available from http:// www.cancer.org/Healthy/FindCancerEarly/. [Accessed May 16, 2012].

18. Ghorbani M, Abdolahi AA, Royani S, Azizi R. Comparison knowledge, attitude and practice of barest self-examination. Iranian Journal of Breast Diseases 2009; 2(3, 4): 36- 42. (Persian). 
19. SaatSaz S, Rezaei R, Nazari R, Haji Hosseini F, SeyediAndi SJ. Effect of educational intervention on condition of knowledge and practice. Iranian Journal of Breast Diseases 2009; 2 (3): 28 - 35. (Persian)

20. Lee EE, Eun Y, Lee SY, Nandy K. Age-Related Differences in Health Beliefs Regarding Cervical Cancer Screening Among Korean American Women. Journal of Transcultural Nursing . 2012; 23 (3): 37-45.

21. Moodi M, Sharifirad GR, Rezaeian M, Mostafavi F. THE EFFECTS OF BREAST CANCER EDUCATIONAL INTERVENTION ON KNOWLEDGE AND HEALTH BELIEFS OF WOMEN 40 YEARS AND OLDER, ISFAHAN, IRAN. Chova LG, Martinez AL, Torres IC, editors. 2012. 588 96-p.

22. Khani H, Moslemizadeh N, Montazeri A, Godazandeh GA, Ghorbani A. Knowledge, attitude and practice of health personnel to prevent breast cancer programs in the southern margins of the Caspian Sea. Iranian Journal of Breast Diseases 2008; 1(2): 28 - 37. (Persian)

23. Ghodazandeh GA, Khani H, Khalilian AR, Atarod Z, Montazeri A, Firozjaee MA, et al. Knowledge and practice related to breast cancer prevention in Iranian female population, multi-center study in 2004. Research Journal of Biological Sciences 2008; 3 (3): 282-291. (Persian).

24. 24)Fazel N, Akbar zadeh R, Estaji Z, Akabery A. Breast self-examination: knowledge, and performance among upper 20 year old women in medical-health centers in Sabzevar-Iran in 2010. Iranian Journal of Breast Diseases 2010; 3 (1): 49-54. (Persian).

25. Aker S, Oz H, Tuncel EK. Practice of Breast Cancer Early Diagnosis Methods among Women Living in Samsun, and Factors Associated with This Practice. Journal of Breast Health. 2015;11 (3):115 - 22.

26. Sim HL, Seah M, Tan SM. Breast cancer knowledge and screening practices: a survey of 1000 Asian women. Singapore Medical Journal 2009; 50 (2): 132 - 138.

27. Parsa P, Kandiah M, MohdZulkefli NA, Rahman HA. Knowledge and behavior regarding breast cancer screening among female teachers in Selangor, Malaysia. Asian Pacific Journal of
Cancer Prevention 2008; 9 (2): 221 - 228.

28. Marmara D, Marmara V, Hubbard G. Health beliefs, illness perceptions and determinants of breast screening uptake in Malta: a crosssectional survey. Bmc Public Health. 2017; 17.

29. Tavafian SS, Hasani L, Aghamolaei T, ZareSh, Gregory D. Prediction of breast selfexamination in a sample of Iranian women: an application of the health belief model. Bio Med Centeral Women's Health 2009; 9 (1): 37. (Persian).

30. Calvocoressi L, Kasl SV, Lee CH, Stolar M, Claus $\mathrm{EB}$, Jones BA. A prospective study of perceived susceptibility to breast cancer and no adherence to mammography screening guidelines in African American and white women ages 40 to 79 years. Cancer Epidemiology Biomarkers Prevention 2004; 13 (12): 2096 - 2105.

31. Karimy M, NiknamiSh, Amin Shokravy F, Shamsi M, Hatami A. The Relationship of breast self-examination with self-esteem and perceived benefits/barriers of self-efficacy in health volunteers of Zarandieh city. Iranian Journal of Breast Diseases 2009; 2 (2): 41- 48. (Persian).

32. Jemal A, Bray F, Center MM, Ferlay J, Ward E, Forman D. Global cancer statistics. CA: a cancer journal for clinicians. 2011; 61 (2): 69 - 90.

33. Moradi Y, Jafari M, Chaichian S, Khateri S, Akbarian A, Moazzami B, et al. Trends in ovarian cancer incidence in Iran. Iranian Journal of Cancer Prevention. 2016; 9 (6).

34. Jahangiry L, ShojaeiZadeh D, Mahmoody M. Application of HBM on studying of knowledge and attitude of women referring to health centers of Azarshahr about prevention of breast cancer 2007. Tolooebehdasht 2007; 6 (3): 65 - 74. (Persian).

35. Reisi M, Javadzadeh SH, SharifiradGh, Yarmohammadi P. Knowledge, attitudes and practice of breast self-examination among female health workers in Isfahan, Iran. Scientific Journal of Health System Research 2011; 7 (2): 190-191. (Persian).

36. Hajian S, Vakilian K, Najabadi KM, Hosseini J, Mirzaei HR. Effects of Education Based on the Health Belief Model on Screening Behavior in High Risk Women for Breast Cancer, Tehran, Iran. Asian Pacific Journal of Cancer Prevention. 2011; 12 (1): 49 - 54. 
ساناز نصيرى اصفهانى و همكاران

37. Ersin F, Bahar Z. Inhibiting and Facilitating Factors Concerning Breast Cancer Early Diagnosis Behavior in Turkish Women: A Qualitative Study According to the Health Belief and Health Development Models. Asian Pacific Journal of Cancer Prevention. 2011; 12 (7): 1849-54.

38. Tsunematsu M, Kawasaki H, Masuoka Y, Kakehashi M. Factors Affecting Breast Cancer Screening Behavior in Japan - Assessment using the Health Belief Model and Conjoint Analysis. Asian Pacific Journal of Cancer Prevention. 2013; 14 (10): 6041 - 8.

39. Roncancio AM, Ward KK, Fernandez ME. Understanding Cervical Cancer Screening Intentions among Latinas Using An Expanded Theory of Planned Behavior Model. Behavioral Medicine. 2013; 39 (3): 66 - 72.

40. Taymoori P, Berry T. The validity and reliability of Champion's health belief model scale for breast cancer screening behaviors among Iranian women. Cancer Nursing 2009; 32 (6): 465 - 472. (Persian).

41. Bakhtari Aghdam F, Noori Zadeh R, Sahebi L. Effect of education based on health belief model in promotion of belief and creation of screening behavior of breast cancer in women referred to health centers in Tabriz. Medical Journal of Medical University of Tabriz 2012; 33 (6): 25 31. (Persian).

42. Miri M, Moodi M, Moasheri B, Sourgi Z, Hami J. A Applied Health Belief Model (HBM) in Adopting Preventive Behaviors in Breast Cancer by Female Teachers of Birjand. Journal of Health Administration 2004; 7 (17): 51 - 7.

43. Navabi Rigi SD, Farnoosh K, Bandani F. Breast cancer and Breast self- examination: acknowledgement and attitude based on health belief model in literature and engineering colleges of Sistan Balochestsn University female students. Quarterly Journal of Breast Disease 2012; 5 (1): 65 - 73.

44. Noori Zadeh R, Bakhtary Aghdam F, Sahebi L. Knowledge, health beliefs and breast cancer screening behaviors of women referring to health centers of Tabriz, 2010. Iranian Journal of Breast Diseases 2010; 3 (3, 4): 43-51. (Persian). 